Author's post-print: P. Pascual-Muñoz, D. Castro-Fresno, P. Serrano-Bravo, A. Alonso-Estébanez. "Thermal and hydraulic analysis of multilayered asphalt pavements as active solar collectors". Applied Energy, 111 (2013) 324-332. ISSN: 0306-2619.

\title{
Thermal and hydraulic analysis of multilayered asphalt pavements as active solar collectors
}

\author{
P. Pascual-Muñoz a *, D. Castro-Fresno ${ }^{\text {a }}$, P. Serrano-Bravo ${ }^{\text {b }}$, A. Alonso-Estébanez ${ }^{\text {a }}$ \\ ${ }^{a}$ Department of Transports, Projects and Processes Technology, Universidad de Cantabria \\ ${ }^{b}$ Department of Applied Physics, Universidad de Cantabria.
}

\begin{abstract}
The fulfillment of current environmental aims like reducing fossil fuel consumption or greenhouse gas emissions entails the development of new technologies that enable the use of cleaner, cheaper and renewable energies. Furthermore, the need to improve energy efficiency in buildings encourages scientists and engineers to find new ways of harvesting energy for later uses. The use of asphalt pavements as active solar collectors is introduced in this article. Several authors have studied the use of roads as an energy source before. However, a new technology is presented in which a multilayered pavement with a highly porous middle layer is used instead of a solar collector with an embedded pipe network. These collectors are fully integrated within the road infrastructure and may offer low cost solar energy for water heating. The paper includes a brief comment on the state-of-the-art. Then, a broad methodology is presented in which data, materials and procedures needed to run the tests are fully described. Finally, the results of the laboratory tests are stated and discussed. The prototype used in the laboratory provided excellent thermal efficiency. However, these good results contrast with the low flow rate levels registered during the tests. Thus, although this technology seems to be very promising, new experimental tests should be performed before an effective application is possible.
\end{abstract}

\section{KEYWORDS}

Asphalt collector, porous layer, irradiance, slope, thermal efficiency.

\section{INTRODUCTION}

The reduction of fossil fuel consumption and greenhouse gas emission to the atmosphere motivates research and development of new energy generation methods: renewable, clean, and respectful of the environment. Asphalt pavements can be heated up to $343 \mathrm{~K}(70 \stackrel{\circ}{\circ})$ by solar irradiation during the summer because of their heat-absorbing property $[1,2]$. Due to these properties and possible uses in parking lots and roadways with adjacent buildings, the supply of thermal energy from asphalt solar collectors is a potential application.

At present, solar energy solutions [3,4] in general and conventional flat-plate collectors [5] for several low temperature applications in particular are widely used. Although these devices have proved to be a suitable technology for those tasks, it is also true that they are costly, constitute a separate entity, need space for their installation and involve a dead load in the building structure. Asphalt collectors attempt to provide a solution to these problems.

Little work is reported in the literature about the areas of design and development of solar collectors made out of construction materials such as asphalt or concrete. Only a few studies have been done. In these 
cases, a pipe network has been placed within concrete slabs or asphalt pavements. The materials used for the tubes include metals such as steel, aluminum and copper or polymers such as polyethylene or PVC.

In these systems, the fluid flowing through the tubes extracts the energy accumulated in the hot asphalt or concrete pavements. Then, this energy may be stored as a low-grade heat reservoir. When necessary, the stored energy can be increased through an auxiliary device such as a conventional furnace.

Three main benefits can be obtained from using solar collectors. They can provide a clean and low-cost energy source for heating buildings or providing domestic hot water. The energy collected in summer can also help to keep the roads free of snow and ice in winter. Finally, the high temperatures in the pavement are reduced by extracting heat in the summer, thus increasing the resistance to permanent deformations and life span.

However, an asphalt collector with embedded tubes implies certain problems. Whenever metallic tubes are used, problems of corrosion and difficulties in on-site installation can occur. When using polymer tubes, the poorer thermal conductivity and the more complicated milling and later re-use of the asphalt mix are important drawbacks. Furthermore, the pavement structure is weakened because of the introduction of a flexible element within a much stiffer material. Finally, occasional leakages in the joints between pipes can occur with both materials. In a road, these problems become more critical since very difficult maintenance has to be performed while the road is closed.

For all these reasons, a new multilayered asphalt pavement has been designed and tested in the laboratory. The middle layer is a highly porous layer, up to $27 \%$ voids, that allows the fluid to circulate through it while part of the energy available in the asphalt mix is harvested.

A multilayered asphalt pavement offers easier on-site installation and more suitable maintenance when necessary. In terms of thermal efficiency, a porous media provides a wider fluid (water) - solid (asphalt) contact area, which entails higher heat transfer efficiency. On the other hand, meticulous waterproofing must be performed to avoid leakage.

An experimental car park with multilayered asphalt solar collectors has been built [6] in which design and construction issues have been considered. This experimental site is still being monitored.

\section{BRIEF BACKGROUND}

Only a few references have been found about research into these non-conventional solar collectors. Most of the papers included in the literature review can be classified according to two different parameters: the material used for the slab (asphalt mix or concrete) and the material of the pipe network inside the slabs (metal or polymer).

The first reference found in the technical literature is the patent obtained by Wendel in 1979 [7]. In this document, a method to heat water by making it flow through a net of metal pipes embedded in as asphalt pavement exposed to solar radiation is described. Two years later, Sedgwick and Patrick [8] develop this application by installing a net of polymer pipes within an asphalt pavement. Results showed how the system was technically feasible at a low cost.

Between the end of the eighties and the beginning of the nineties, several authors continued working on this topic $[9,10,11]$. Mathematical models and/or real-scale tests were carried out to investigate the energy performance and suitability of this type of systems.

Al-Saad et al. [12] reported the development, manufacturing and testing of non-conventional flat plate concrete collectors. Three different concrete collectors were constructed according to the material of the 
network of tubes located inside: steel and two different polymers. An efficiency of $40 \%$ was obtained and the collector with steel pipes provided the best performance.

In the mid-nineties, two systems capable of melting ice on roads or preventing its formation were developed in Japan and Switzerland: the GAIA and SERSO systems, respectively. In both cases, the energy absorbed by the pavement during the summer is partially recovered by water flowing through a network of pipes embedded in the asphalt pavement and stored in the ground by means of several boreholes. This energy is used in winter to de-ice the pavement surface.

The effect of cooling and heating asphalt pavements on their durability was studied by Van Bijsterveld et al. [13]. Thermal analyses were performed with a finite element model based on real data from a field test. Polymer tubes were placed inside an asphalt pavement to monitor its temperature over time. It was determined that the depth of the tubes within the asphalt layer is an influential factor for effective operation.

As a result of this research, the Road Energy Systems (RES) concept arose in The Netherlands in 2001. The energy exchanged in summer and winter between the pavement and the ground (aquifers) allows this system to provide heating and cooling to a building. In the United Kingdom, similar technology called International Heat Transfer (IHT) was developed in 2007.

Chaurasia [14] presented a study in which solar concrete collectors were tested as domestic hot water suppliers. The collectors were made of thin concrete slabs with a network of aluminum pipes embedded over their surfaces. The results showed that these low-cost and easy-to-fabricate collectors can obtain water at moderate temperature.

More recently, Sarachitti et al. [15] studied the thermal performance of a roof-integrated solar concrete collector with embedded polymer pipes. Up to 40 liters per day of hot water at temperatures between 313

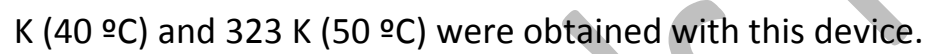

Mallick et al. $[16,17]$ developed a finite element model to study temperature distribution in asphalt slabs. Small and large-scale asphalt samples with a frame of copper tubes inside were tested as solar collectors. The results showed how the use of aggregates with high values of conductivity can enhance the collection efficiency and that the depth of the copper pipes frame is critical.

Concerning the use of enhanced asphalts, Wu et al. [18] and Chen et al. [19] concluded that the heat transfer from the top to the bottom of asphalt slabs becomes faster when graphite powder is added. Therefore, an increase of the collector efficiency is obtained. Besides, the addition of this conductive filler can help to reduce the extreme temperature distribution fluctuations in asphalt pavements.

In order to determine which parameters were critical in the behavior of an asphalt collector, a numerical simulation was developed by Wang et al. [20] in which a model of an asphalt collector with a net of rubber pipes in its middle layer was used to predict the thermal response of these devices. In 2011, Wu et al. [21] investigated the process of extracting thermal energy from asphalt slabs with u-shaped metal tubes inside. It was proved that the circulating water can decrease the surface temperature of the asphalt mix, reducing the risk of permanent deformation and the urban heat island effect.

The results collected in [18-21] served Chen et al. [22] to investigate about the snow melting process on asphalt pavements when working as solar collectors. An experimental study was carried out in which the temperature distribution in enhanced asphalt slabs with a net of pipes embedded was analyzed during a snow melting process. The results showed that a low temperature of the circulating water is enough for this system to work properly. 
Finally, two very interesting review papers were published recently. In 2012, a thorough review of the socalled Massive Solar-Thermal Collectors was presented [23]. Thus, while these systems are mostly integrated in building structures, a review paper has been published in 2013 in which a detailed state of the art concerning the asphalt thermal behavior, and the variables involved in the solar energy collection by pavements is presented [24].

\section{RESEARCH METHODOLOGY}

\section{Energy Balance: Heat Collection Mechanism}

An energy balance exists in the surface of the asphalt pavement that allows the pavement to collect thermal energy by increasing its temperature. When the pavement is part of a multilayered solar collector, the energy balance including heat transfer by radiation, convection and conduction can be schematically represented as shown in Fig.1.

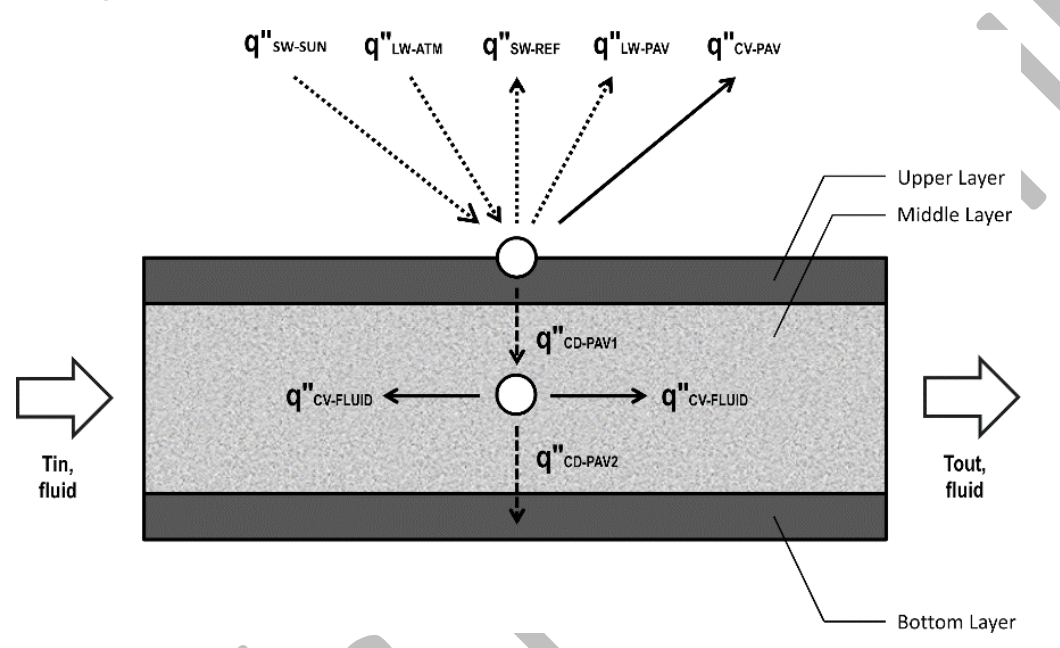

Fig. 1 - Energy balance in a multilayered solar collector.

Several elements form part of the radiation balance between the surface pavement and its surroundings. Thus, the shortwave radiation from the sun (direct and diffusely scattered in the atmosphere) reaching the pavement is represented by q"sw-SUN. A portion of this radiation, q" ${ }^{\prime \prime}$-REF, is reflected back depending on the surface albedo. q" LW-PAV refers to the outgoing longwave radiation emitted by the pavement, while q" represents the fraction of the longwave radiation leaving the pavement which is absorbed by the atmosphere and partly emitted back to the pavement.

On the other hand, the different temperatures existing in the interphase between the pavement surface and the adjacent air result in the convective heat flux represented by q" ${ }^{\prime}$-PAv and lead to convection losses from the pavement to the atmosphere.

Finally, q"CD-PAV1 represents the heat absorbed by the pavement which is transferred by conduction to deeper layers. The temperature distribution obtained this way is governed by the transient heat conduction equation [23] and is dependent on the parameters specific heat $\left(C_{p}\right)$ and conductivity $(\lambda)$. Its suitable value of $C_{p}$ allows the asphalt collector to store a high amount of solar energy while its relatively good value of $\lambda$ ensures that the stored energy is transferred to deeper layers [23].

Regarding the energy exchange in the middle porous layer, q" ${ }_{\text {cV }}$-fLuID refers to the convective heat flux between the pavement and the fluid circulating through the pores. This flux is responsible for the raise of water temperature and depends on the heat conduction rate q" $\mathrm{CD}^{\mathrm{PAV} 1}$ coming from the upper layer and the heat conduction rate $\mathrm{q}^{\prime \prime} \mathrm{CD}-\mathrm{PAV} 2$ transferred to the bottom layer. 


\section{Properties of the laboratory prototypes}

A prototype of the multilayered solar collector was used in the laboratory. The dimensions of the slab were $40 \mathrm{~cm} \times 26 \mathrm{~cm} \times 9 \mathrm{~cm}$ (length $\times$ width $\times$ thickness), which means that this prototype is between 25\% and $40 \%$ thinner than the asphalt (and concrete) solar collectors tested in the last years [15-18,21,22]. Two different models of this prototype were manufactured, each with a different porosity in its middle layer: $23 \%$ and $27 \%$ voids.

The middle layer of the slab is made up of a highly porous mix. It is $4 \mathrm{~cm}$ thick and a Porous Asphalt with a maximum aggregate size of $16 \mathrm{~mm}$ (PA16) has been used. This is technically the most difficult layer to fabricate in the laboratory due to its high permeability. For this reason, a modified high-viscosity bitumen was used that enabled permeabilities of $2.87 \cdot 10-3 \mathrm{~m} / \mathrm{s}$ for the mix with $23 \%$ voids and $4.23 \cdot 10-3 \mathrm{~m} / \mathrm{s}$ for the mix with $27 \%$ voids. Besides, the use of this kind of bitumen improves its resistance to possible plastic deformations caused by traffic loads [25]. This layer allows the fluid to circulate through it while collecting part of the thermal energy available in the asphalt mix.

The upper layer is $2 \mathrm{~cm}$ thick and was manufactured with an asphalt concrete for very thin layers (BBTM). It keeps the rainwater away from the middle layer, thus avoiding leakage of the fluid flowing through the middle layer, and receives the solar radiation. This surface layer also enables vehicles to drive over it. Finally, the bottom layer is needed because proper waterproofing is required to avoid serious damage caused to the deeper layers of the road by dropping water. It is $4 \mathrm{~cm}$ thick and made with an asphalt concrete with a maximum aggregate size of $16 \mathrm{~mm}$ (AC16). More properties of the mixes used in the slab are shown in Table 1, where the two types of middle layers are included.

Table 1 - Properties of the asphalt mixes used to manufacture the multilayered asphalt collector prototype

\begin{tabular}{|c|c|c|c|c|c|}
\hline $\begin{array}{l}\text { Type of } \\
\text { Layer }\end{array}$ & $\begin{array}{c}\text { Voids } \\
\text { Content } \\
(\%)\end{array}$ & $\begin{array}{c}\text { Mix } \\
\text { Gradation }\end{array}$ & $\begin{array}{c}\text { Mix } \\
\text { Density } \\
\left(\mathrm{g} / \mathrm{cm}^{3}\right)\end{array}$ & $\begin{array}{l}\text { Type of } \\
\text { Bitumen }\end{array}$ & $\begin{array}{c}\text { Bitumen } \\
\text { Content } \\
\text { (\%) }\end{array}$ \\
\hline Upper Layer & 4.41 & Gap-graded & 2.37 & Conventional & 5.30 \\
\hline Middle Layer 1 & 23.57 & Open-graded & 1.91 & Modified & 4.33 \\
\hline Middle Layer 2 & 27.53 & Open-graded & 1.79 & Modified & 4.10 \\
\hline Bottom Layer & 4. & Dense-graded & 2.68 & Conventional & 4.93 \\
\hline
\end{tabular}

\section{Experimental Set-Up}

To satisfy the thermal and hydraulic conditions needed for the tests, a device was designed to provide a kind of a constant head permeameter. This device allows the heating fluid to circulate through the middle layer of the solar collector prototype, while keeping the inlet hydraulic head constant over time and providing an infinite recharge/refill. It is also able to regulate the inlet $\left(\mathrm{H}_{\text {in }}\right)$ and outlet $\left(\mathrm{H}_{\text {out }}\right)$ head, thus obtaining the different hydraulic gradients $(\Delta \mathrm{H})$ which provide the different flow rates and, finally, the different hydraulic head regimes. Schematic views of the two possible configurations of the device are shown in Fig. 2.

The first case corresponds to a configuration in which a hydraulic gradient $(\Delta H)$ has been fixed to make the middle layer saturated during the whole test. In other words, the fluid level is always over the intermediate layer level. In the second configuration, the hydraulic level $(\Delta \mathrm{H})$ chosen makes the middle layer only partially saturated, reducing the pressure on the upper layer. 

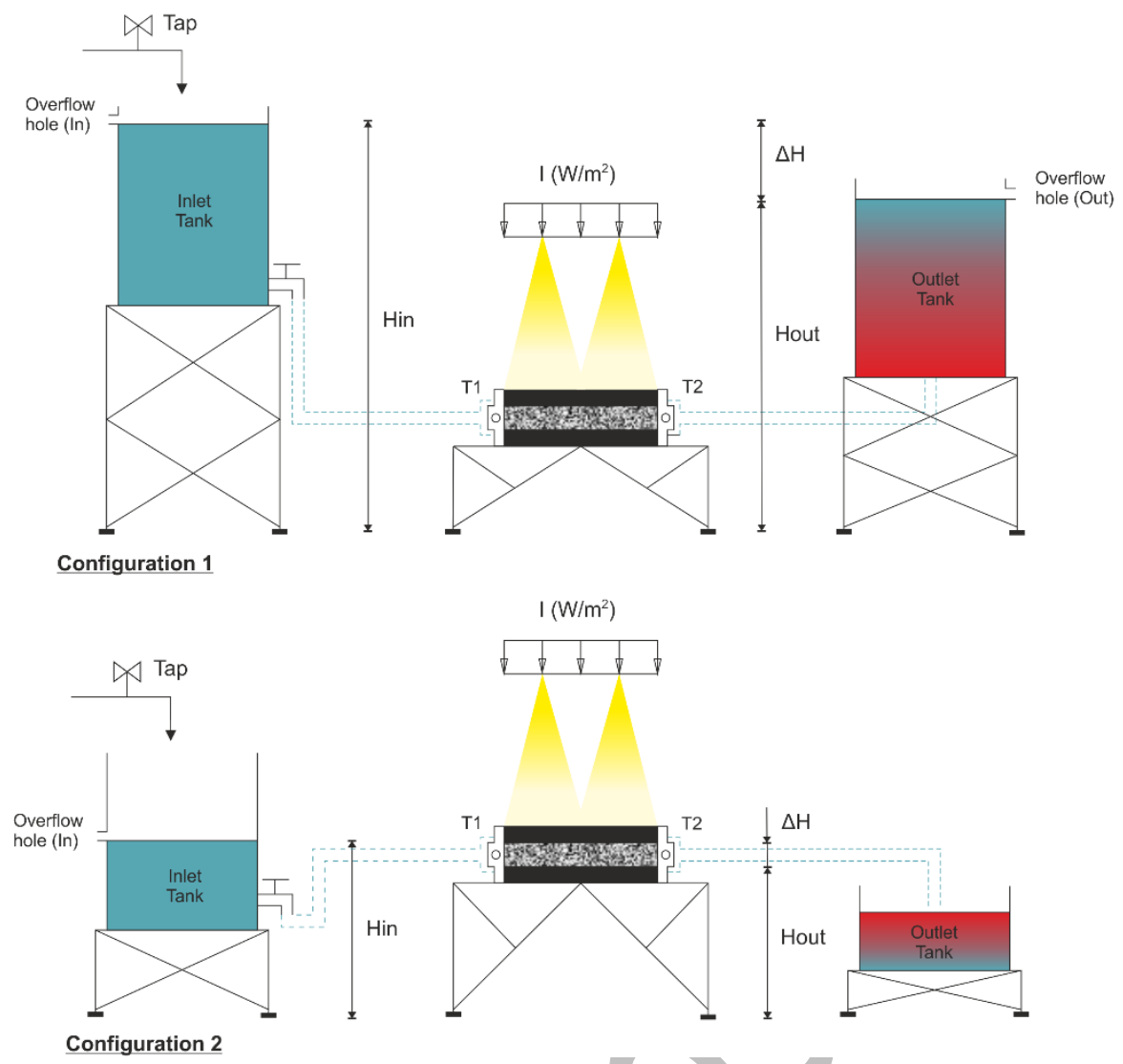

Fig. 2 - Schematic view of the two configurations for the experimental set-up.

A previous test was carried out in which these two configurations were evaluated. Results showed that the upper layer was unable to keep the middle layer waterproof when the first configuration of the device was tested. Thus, the upper layer could not avoid the water rising up to the surface. For this reason, the first configuration was rejected and only the second was used for the subsequent tests.

From the thermal point of view, both configurations were able to emulate the working conditions of a multilayered solar collector when it is subjected to the energy balance existing on its surface. Since tests have been done in a laboratory, issues such as evaporation and condensation affecting the surface of the asphalt pavements have not been taken into account.

To determine the suitability of this type of asphalt collectors, several measurements have been carried out in the laboratory. A testing device was implemented that enables these measurements to be done on the solar collector prototype according to the analysed configurations. A solar simulator lamp was used to simulate the solar effect on the collector.

The inlet and outlet water tanks are in charge of keeping the fluid level constant for any hydraulic gradient $(\Delta \mathrm{H})$ chosen. An overflow hole cut in the tanks provides easy hydraulic head regulation just by raising or lowering the tanks. In turn, the inlet water tank is supplied with fresh water from storage tanks, where the inlet temperature is properly controlled. A specially designed methacrylate device allows the water to circulate through the middle layer of the prototype. It is formed by an element that distributes the inlet water and another element that collects the outlet water and lets it leave the prototype. The prototype perimeter is insulated by extruded polystyrene foam and resistant and rigid rubber plate is placed at the bottom.

The irradiance $(\mathrm{W} / \mathrm{m} 2)$ source on the solar collector surface was a solar simulator lamp. The lamp is made up of a portable steel structure with four special radiator bulbs $(300 \mathrm{~W})$ arranged in the form of a $2 \times 2$ 
matrix. For bigger prototypes, another lamp was developed with 16 of these bulbs arranged in the form of a $4 \times 4$ matrix. Both installations enable the lamp height to be varied to provide different values of irradiance. The radiation produced by these special bulbs is similar in its composition to solar radiation. It is generated by a tungsten filament and a high-pressure lamp. The special glass covering the filament ensures that the lamp only emits the ultraviolet radiation contained in the solar radiation. These special radiator bulbs have been used in a wide range of applications, including glass testing [26], chemical compound degradation [27] or simulation of other atmospheric processes [28].

The measurement instruments used during the lab tests were: three temperature probes, one to determine the inlet water tank temperature $\left(T_{i w}\right)$, and two more probes to measure the inlet $\left(T_{i}\right)$ and outlet $\left(T_{0}\right)$ water temperature. A laser thermometer and a pyranometer were used to measure the surface temperature $\left(T_{s}\right)$ and irradiance $(I)$, respectively. Finally, temperature and humidity sensors were also used to determine the humidity $(h)$ and temperature $\left(T_{e}\right)$ of the laboratory. Apart from the flow rate (q), calculated by determining the time taken for the outlet water to fill up a fixed volume of a graduated cylinder, and the surface temperature, all the measurements were taken automatically.

\section{Experimental Procedure}

Once the experimental set-up configuration was chosen by means of the previously mentioned stage, the work carried out in the laboratory was divided into two more stages. The first one, in which the influence of the variables porosity (\% voids) of the middle layer and irradiance $(\mathrm{W} / \mathrm{m} 2)$ on the solar collector behaviour was evaluated and the second one, in which the influence of the variable slope (\%) was analysed.

Concerning the first stage, tests with three different values of irradiance were carried out on the two prototypes with different values of porosity. The values of irradiance used were 300,373 and $440 \mathrm{~W} / \mathrm{m} 2$, while the values of porosity corresponded to the porosity of the middle layer of the two models of solar collector prototypes manufactured: 23 and $27 \%$. The duration of the tests was 6 hours, a $0 \%$ slope was established for all of them and 3 repetitions were done for each combination of irradiance and porosity and each prototype.

The objective of the second stage was to determine the influence of an increase in the slope on the thermal and hydraulic behaviour of the prototype with a porosity of $27 \%$ voids in its middle layer. The values of slope used in the tests were $0 ; 0.5$ and $1 \%$. Their duration was 6 hours, a value of irradiance of $373 \mathrm{~W} / \mathrm{m} 2$ was fixed for all the tests, which were repeated three times for each value of slope and each prototype. The application of higher slopes is limited since this system has to be installed as part of a road or car park.

For every test, the following values were obtained: q measured in litres/second $(1 / s) ; T_{s}$ measured in Kelvin $(\mathrm{K}) ; \mathrm{T}_{\mathrm{e}}$ measured in Kelvin (K); $\mathrm{h}$ measured in percentage (\%); and temperature gradient $\Delta \mathrm{T}$ measured in Kelvin $(K)$, which was the difference between the inlet and the outlet water temperatures. The outlet power $\left(\mathrm{Q}_{\text {out }}\right)$ measured in watts $(\mathrm{W})$, the generated energy $\left(\mathrm{E}_{\text {out }}\right)$ measured in Joules $(\mathrm{J})$ and the thermal efficiency $(\eta)$ of the prototype, were calculated using the data.

The expression used to calculate the outlet power after every test is the following:

$$
Q_{\text {out }}=q \cdot\left(\rho_{f} \cdot C_{p}\right) \cdot \Delta T
$$

Where $C_{p}=4186$ is the specific heat $(\mathrm{J} / \mathrm{kgK})$ of the water circulating through the middle layer of the collector and $\rho_{\mathrm{f}}$ is its density $(\mathrm{kg} / \mathrm{m} 3)$.

Then, the energy absorbed by the water can be calculated as the area under the power-time curve, given by integration. In this case, to numerically determine its value after every test, the Trapezium Rule was 
used. Finally, the efficiency can be calculated as the relationship between the energy transferred to the fluid and the energy absorbed by the surface of the solar collector $\left(E_{\text {in }}\right)$. The equation is the following:

$$
\eta(\%)=\left(E_{\text {out }} / E_{\text {in }}\right) \cdot 100
$$

From the results obtained in the tests, descriptive and statistical analyses of variance (ANOVA) were carried out with the software SPSS Statistics v.19. The level of significance of the porosity and its effect on the measurements of $q, \Delta T$ and total water volume $\left(V_{W}\right)$ were analysed. The level of significance of the slope and its effect on the measurements of maximum $\Delta T$ and $V_{W}$ were also analysed.

Apart from collecting thermal energy, this system can contribute to reduce the local heat island effect in urban areas by removing the absorbed solar radiation and, hence, lowering the surface temperature of the pavement. In order to support this assumption, the temperature reached by the collector surface was measured over time in four single tests with different conditions: prototype with $23 \%$ voids in the middle layer and a slope of $0 \%$; prototype with $27 \%$ voids and slopes of $0 \%$ and $1 \%$; and, finally, prototype with $27 \%$ voids through which no water is circulating (control test). The same irradiance was applied (370 $\mathrm{W} / \mathrm{m} 2$ ) in all these tests.

\section{RESULTS AND DISCUSSIONS}

The first results to be analysed were the variations of the water flow rate as a function of the porosity and time. The relative flow rates ( $1 / \mathrm{s}$ per $\mathrm{m} 2$ ) obtained in the tests for the solar collector models with $23 \%$ and $27 \%$ voids in their intermediate layers are shown in Fig. 3.

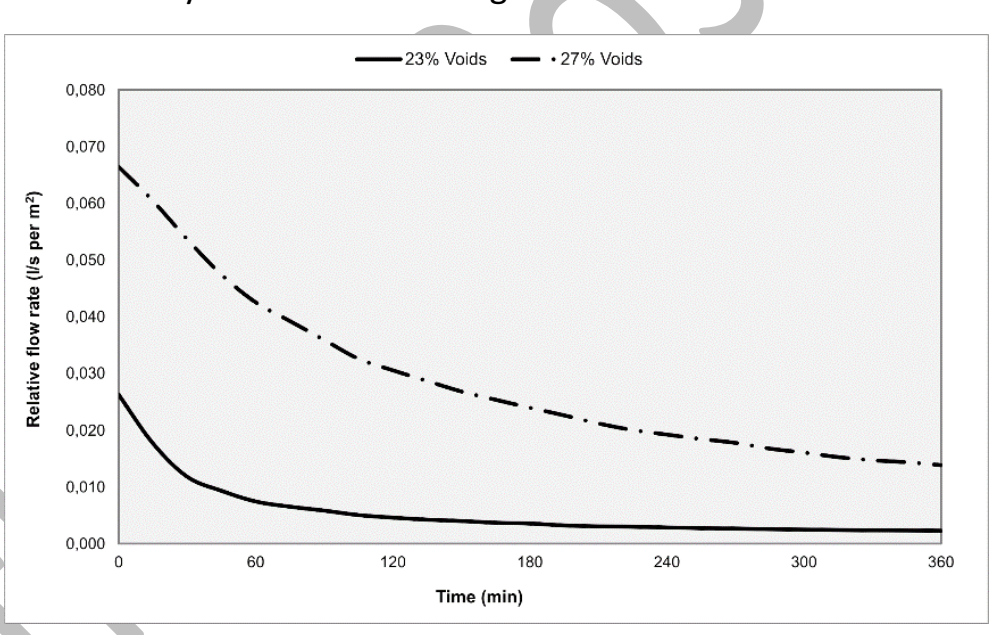

Fig. 3 - Effect of the porosity on the flow rate as a function of time.

It can be clearly appreciated that in both cases the relative flow rate values decrease with increasing test time as they are under a transient regime. The figure also shows that higher porosity of $27 \%$ leads to higher flow rate during the whole test, with an average difference of 6 times the porosity of the model with $23 \%$ voids in its middle layer.

Flow rate results has been presented in terms of relative or specific figures (related to the prototype surface area) in order to highlight the importance of the geometry (and design) of this kind of solar collectors. Thus, although the absolute flow rate figures obtained are considerably lower than those used by Wu et al. $[18,21]$ and Chen et al. [22] in their tests, and Van Bijsterveld et al. [9] in their simulations, the nature of the multilayered asphalt pavements allows the flow rate to be increased when the collector width is increased. 
Furthermore, once the need for a higher flow rate was previously established, two more alternatives were considered to achieve the objective: firstly, increasing the middle layer porosity and secondly, increasing the collector slope. Both solutions where studied, put into practice and their results displayed in this paper.

The effect of the irradiance variation on the flow rate as a function of time was also studied for both models with $23 \%$ and $27 \%$ voids, but no significant variations were found for the different values of irradiance used. This means that the temperature reached by the water in the laboratory tests was not high enough so as to affect its viscosity and, therefore, its hydraulic behaviour.

Regarding the statistical analysis of the porosity, the ANOVA test resulted in a p-value lower than the predetermined level of significance $\alpha=0.05$, confirming that porosity is a significant variable. Thus, the flow rate and the total volume of water heated up by the collector depend significantly on the porosity of the middle layer prototype.

The curve in Fig. 4 represents $\Delta T$ as a function of the middle layer porosity and time. In this case, both curves refer to the average $\Delta T$ curves obtained for the different values of irradiance used. Maximum values of $6 \mathrm{~K}$ were obtained which are much higher than those reported by Wu et al. [18,21]. When comparing for similar flow rate conditions, $\Delta T$ values obtained with the multilayered asphalt collectors are still higher. Since the areas of both slabs are similar and the value of irradiance used by Wu et al. [18] was even higher, the multilayered asphalt collector thermal efficiency has demonstrated to be higher.

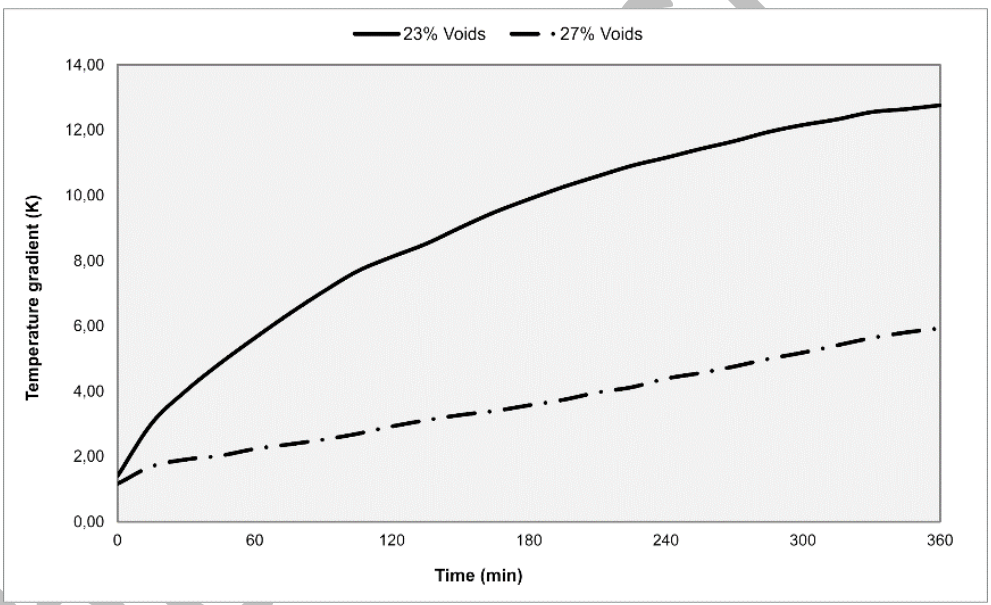

Fig. 4 - Effect of the porosity on the temperature gradient as a function of the time.

When the data of $\Delta T$ are analysed together with the data of flow rate, it can be concluded that a flow rate increase leads to a temperature gradient decrease. Thus, the very high temperatures gained by the water when circulating through the collector with $23 \%$ voids are directly linked to the very low flow rate values obtained in that collector. At the same time, the high increase in the flow rate in the second model of collector ( $27 \%$ voids) leads to an obvious decrease in the temperature gained by the water circulating through that collector. The reason is the shorter stay of the water inside the intermediate layer and, therefore, the shorter time to collect the energy. In this regard, the same tendency was obtained for the asphalt collectors with metal or polymer pipes tested before $[13,16,18,21]$.

A new ANOVA test resulted in a $p$-value lower than the predetermined level of significance $\alpha=0.05$, again confirming that porosity is a significant variable. This means that the average $\Delta T$ or, in other words, the temperature gained by the water while crossing the collector's middle layer depends significantly on the porosity of that layer. 
Apart from the trends shown in the curves above, it is also important to discuss the values of water temperature reached during the tests. The design of any kind of solar collector always entails the need for a sufficiently high temperature so that the energy can be properly applied. Maximum temperatures of 300 and $307 \mathrm{~K}$ were reached by the water for the prototypes with $23 \%$ and $27 \%$ voids in its middle layer, respectively. It should be considered that these results were obtained with prototypes of reduced dimensions and the application of low-medium values of irradiance that led to maximum surface temperatures during the test of 316 and $310 \mathrm{~K}$, respectively. Thus, a longer collector subjected to a real and, hence, higher irradiance will result in a higher temperature of its upper layer $[1,2]$ and a longer period of the water inside its porous layer. Accordingly, a real application of the multilayered asphalt collector will be expected to provide a much higher outlet water temperature. However, this is an engineering question which should be dealt with when the collector length is defined.

Obviously, all these engineering issues presuppose that the collectors' efficiency is high enough so as to be able to take advantage of the solar energy reaching the road. The relation between the energy absorbed by the surface of the collector and the energy gained by the water is shown in Fig. 5. Accordingly, the efficiencies obtained by the collectors as a function of their middle layer porosity and the irradiance applied during the tests are shown in Fig. 6.

As can be seen in Fig. 5 , the $E_{\text {out }}$ obtained for the two models with $23 \%$ and $27 \%$ voids in their intermediate layer grows with the increasing value of the energy absorbed by their surface. However, the trend followed by the $E_{\text {out }}$ obtained for the collectors with higher porosity rises with higher slope. That means that the lower the flow rate, the more difficult is for the heat transfer fluid to collect the energy. Van Bijsterveld et al. [13] and Wu et al. [21] reported curves with similar trends. In both cases, the maximum extracted energy increases as flow rate increases. This conclusion can also be drawn from the resulting efficiencies, with values that are always higher than $75 \%$ for the prototypes with $27 \%$ voids in its middle layer, and a maximum value of $85 \%$.

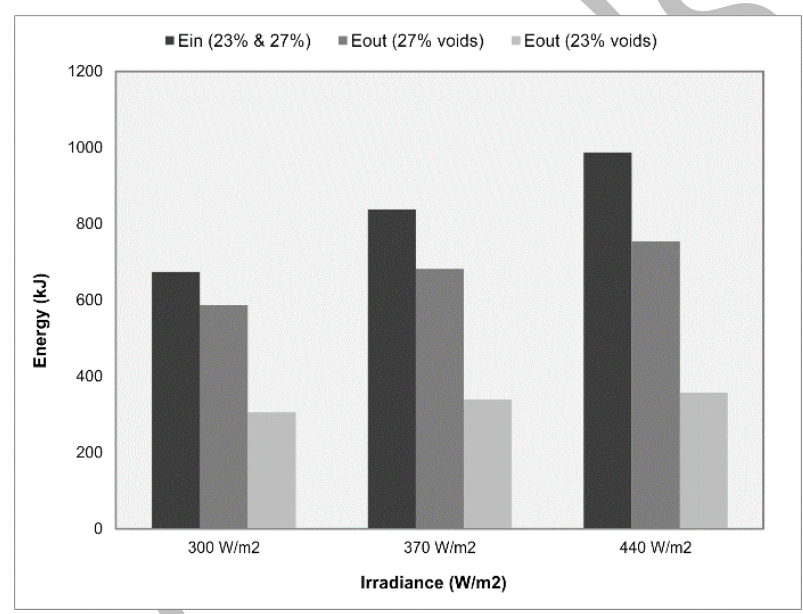

Fig. 5 - Effect of the porosity and irradiance on the energy transferred to the heat transfer fluid (water).

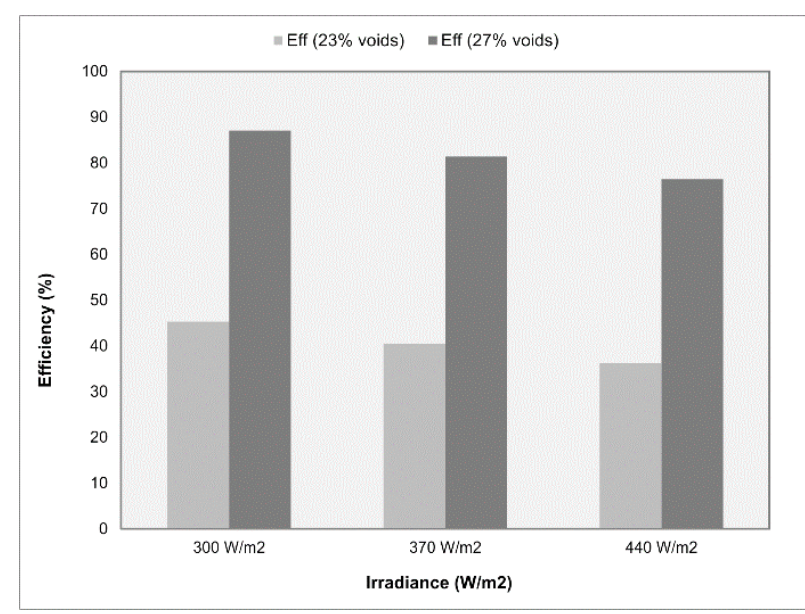

Fig. 6 - Effect of the porosity and irradiance on the multilayered solar collector efficiency.

With these good efficiencies, a suitable increase of the collector slope was applied to try to increase the circulating water flow rate. The effect of applying a higher slope on the relative flow rate $(\mathrm{l} / \mathrm{s}$ per $\mathrm{m} 2)$ is displayed in Fig. 7. The curves in this figure confirm the previous behaviour of the solar collectors as far as their flow rate is concerned: a decrease of this parameter occurs over time as corresponds to a transient regime. On the other hand, the relative flow rate grows as the value of the slope rises from $0 \%$ to $1 \%$. Furthermore, it seems as if a higher flow rate is obtained when the slope is increased from $0 \%$ to $0.5 \%$ than 
when it is increased from $0.5 \%$ to $1 \%$. Nevertheless, further research has to be carried out in order to confirm this phenomenon.

The curves in Fig. 8 show, in turn, how the temperature gradient $\Delta T$ is affected by the increasing slopes during the test. It is clearly observed in this figure that the increase in flow rate with the slope over time leads to a decrease in the corresponding $\Delta T$. As in the tests done before, it is due to the shorter time that the water stays in the porous layer of the solar collectors.

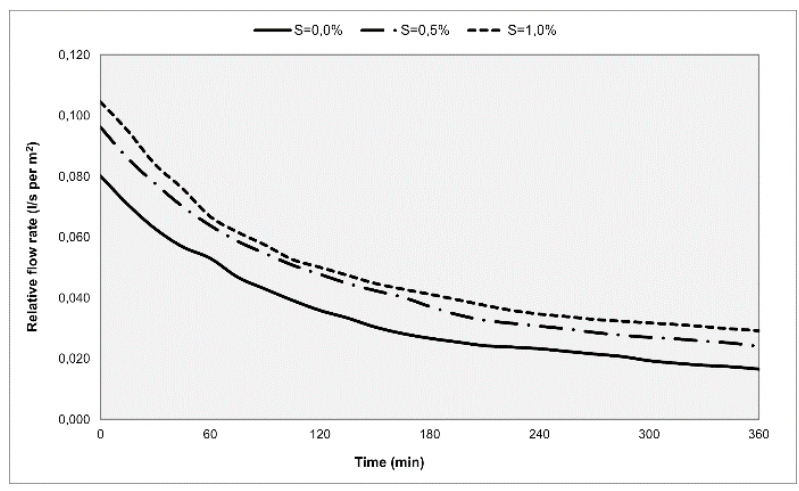

Fig. 7 - Effect of the slope on the flow rate as a function of the time.

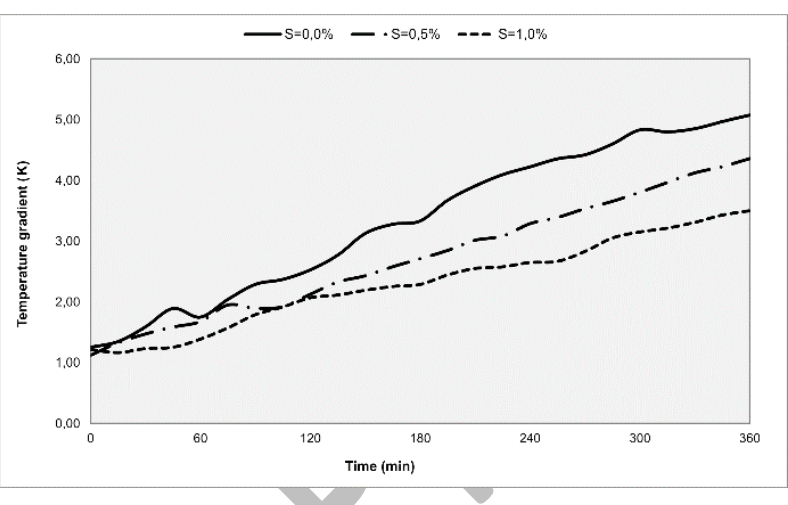

Fig. 8 - Effect of the slope on the temperature gradient as a function of the time.

From these results, a statistical analysis of the slope was performed by means of an ANOVA. This test resulted in a $p$-value lower than the predetermined level of significance $\alpha=0.05$, confirming the slope as a significant variable. Thus, the total water volume which circulates through the collector during the test and the average temperature gained by that water depends significantly on the collector slope.

The efficiencies obtained by the collector as a function of the slope are shown in Fig. 9. Excellent values of up to $95 \%$ were achieved for a multilayered solar collector with a porosity of $27 \%$ voids in its intermediate layer and a slope of $0.5 \%$. These figures suggest that the extra cost associated to the use of conductive fillers $[18,19,21]$ and to the search of more conductive aggregates $[12,13]$ only available in some regions of the country, could be avoided. On the other hand, the fact that the highest efficiency strictly corresponds to the intermediate value of slope tested cannot be confirmed as a design criterion until further research is carried out. In general terms, the application of a slope to a collector which forms part of a road or a car park has another advantage. A slope will allow the collector to remove the residual water, thus avoiding the damage associated with frozen water.

Finally, once the relationship among the flow rate, the energy gained by the water and the efficiency of a multilayered solar collector has been established for the different variables studied (irradiance, porosity and slope), the surface temperature of the collector was analysed as a function of the four different working conditions previously indicated.

As can be seen in Fig. 10, the lowest temperatures were reached in the surface of the collector with the highest permeability and in which the slope was applied. It should be noted that, in this case, most of the temperature increase was induced at the beginning of the test, an almost flat curve being displayed thereafter, and keeping from that moment a linear behaviour. This temperature profile was found to be consistent with the results obtained by Wu et al. [21], where a rapid increase of the temperature gradient was also followed by a steady state. Although a higher reduction in the surface temperature was obtained with the multilayered asphalt collector at the end of the test, the irradiance during these tests was lower and therefore the results cannot be directly compared. 


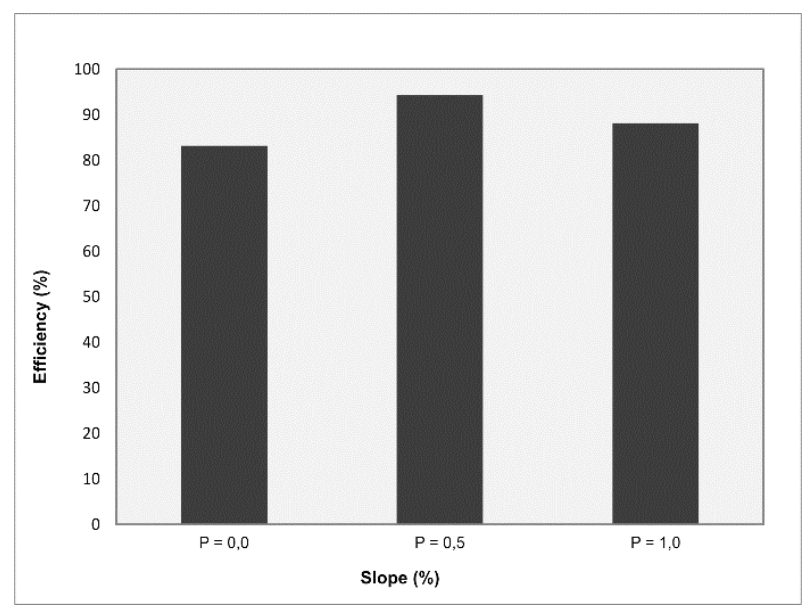

Fig. 9 - Effect of the slope on the multilayered solar collector efficiency.

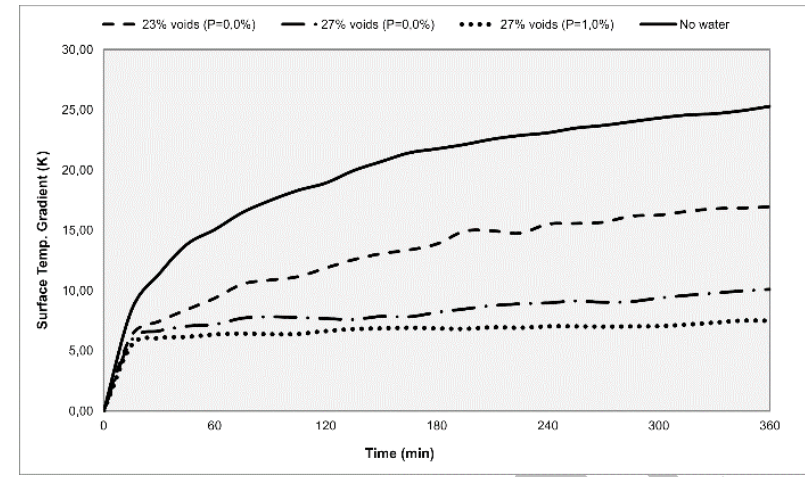

Fig. 10 - Effect of the porosity and slope on the surface temperature increase as a function of the time.

In any case, simply by making water circulate through the middle layer led to a very important decrease in the surface temperature. Global use of these kinds of collectors could entail the reduction of the environmental temperature in urban areas and, finally, a mitigation of the urban heat island effect.

\section{CONCLUSIONS}

A design of a multilayered asphalt solar collector was described in this paper as well as the analysis of some of the most important parameters involved in the collector behavior. Several conclusions can be drawn:

- Excellent thermal efficiencies of the multilayered asphalt collector were obtained in the laboratory tests. Efficiency values from $75 \%$ up to $95 \%$ were obtained depending on the irradiance from the solar lamp, porosity of the intermediate layer and slope applied to the collector.

- The efficiencies obtained suggest that the addition of materials such as graphite, used to enhance the thermal properties of the asphalt, is not necessary.

- Despite the excellent thermal behavior of the solar collector, low flow rates of the heat transfer fluid (water) were achieved in the tests. Thus, although an increase in the middle layer porosity and the application of greater slopes led to higher flow rates, further research should be done with the aim of studying new ways of increasing the flow rate.

- The collector geometry has to be adequately calculated so that the system can work efficiently. Besides, a proper waterproof should be accomplished.

- The inclusion of these asphalt solar collectors in urban areas in the form of roads or parking lots would entail a decrease in the ambient temperature of the area and the mitigation of the urban heat island effect.

\section{ACKNOWLEDGEMENTS}

This paper is based on the initial literature review for the Fenix Project. The development of the Fenix Project (www.proyectofenix.es) has been possible thanks to the financial contribution of the Center for Technological and Industrial Development (CDTI) within the framework of the Ingenio 2010 programme, through the CENIT Programme. The companies and research centers involved in the project wish to express their gratitude for the contribution.

The authors are grateful to all organizations and companies participating in the Fenix Project: Centro de Investigación Elpidio Sánchez Marcos (CIESM), Centro Zaragoza, Construcciones y Obras Llorente (Collosa), Ditecpesa, Asfaltos y Construcciones Elsan, Intrame, Pavasal, Repsol YPF, Sacyr, Serviá Cantó, Sorigué, 
CARTIF, CEDEX, CIDAUT, CSIC (IIQAB), GIASA, Intromac, Labein, Universidad de Alcalá de Henares, Universidad Carlos III de Madrid, Universidad de Castilla La Mancha, Universidad de Huelva, Universidad de Cantabria, Universidad Politécnica de Cataluña, Universidad Politécnica de Madrid, and our many partners whose work capacity and effectiveness have enabled the development of this project in an environment of cooperation.

\section{REFERENCES}

[1] Utilization of steel slag as aggregates for stone mastic asphalt (SMA) mixtures. Wu, S., Xue, Y., Ye, Q. and Chen, Y. Building and environment, 2007, 42(7) 2580-2585.

[2] Al-Saad, M.A., Jubran, B.A. and Abu-Faris, N.A. Development and testing of concrete solar collectors. Solar Energy, 1994, 16 pp. 27-40.

[3] Balghouthi, M., Chahbani, M.H. and Guizani, A. Investigation of a solar cooling installation in Tunisia. Applied Energy, 2012, 98 pp. 138-148.

[4] Gholamalizadeh, E. and Mansouri, S.H. A comprehensive approach to design and improve a solar chimney power plant: A special case - Kerman project. Applied Energy, 2013, 102 pp. 975-982.

[5] Duffie, J.A. and Beckman, W.A. Solar Engineering of Thermal Processes. John Wiley \& Sons. 2006. ISBN13: 978-0471698678.

[6] Cortes, C., Rios, C., Cadenas, J.M., Garcia, C., Pascual, P., Vega, A., Castro, D. and Potti, J.J. Sustainable Asphalt Pavements. Proceedings of 5th Eurasphalt \& Eurobitume Congress, Istanbul (Turkey), 2012.

[7] Wendel, I.L. Paving and solar energy system and method. United States Patent, Patent number 4.132.074, 1979. U.S.

[8] Sedgwick, R. H. and Patrick, M. A. The use of a ground solar collector for swimming pool heating. Solar World Forum. Proceedings of ISES, Brighton (England), 1992, pp. 632-636.

[9] Turner, R.H. Concrete slabs as summer solar collectors. Proceedings International Heat Transfer Conference, 1987, pp. 683-689.

[10] Bopshetty, S.V., Nayak, J.K. and Sukhatme, S.P. Performance analysis of a solar concrete collector. Energy Conversion Management, 1992, 33(11) 1007-1016.

[11] Sokolov, M. and Reshef, M. Performance simulation of solar collectors made of concrete with embedded conduit lattice. Solar Energy, 1992, 48(6) 403-411.

[12] Al-Saad, M.A., Jubran, B.A. and Abu-Faris, N.A. Development and testing of concrete solar collectors. Solar Energy, 1994, 16(1) 27-40.

[13] Van Bijsterveld, W.T., Houben L.J.M., Scarpas, A. and Molenaar, A.A.A. Using pavement as solar collector: effect on pavement temperature and structural response. Journal of Transportation Research Board, 2001, (1778) 140-148.

[14] Chaurasia, P.B.L. Solar water heaters based on concrete collectors. Energy, 2000, 25(8) 703-716.

[15] Sarachitti, R., Chotetanorm, C., Lertsatitthanakorn, C. and Rungsiyopas, M. Thermal performance analysis and economic evaluation of roof-integrated solar concrete collector. Energy and Buildings, 2011, 43(6) 1403-1408. 
[16] Mallick, R.B., Chen, B.L., Bhowmick, S. and Hulen, M.S. Capturing solar energy from asphalt pavements. International ISAP Symposium on Asphalt Pavements and Environment. Switzerland, Zurich, 2008, pp. 161172.

[17] Mallick, R.B., Chen, B.L. and Bhowmick, S. Reduction of urban heat island effect through harvest of heat energy from asphalt pavements. International Journal of Sustainable Engineering, 2009, 2(3) 214-228.

[18] Wu, S., Chen, M., Wang, H. and Zhang, Y. Laboratory study on solar collector of thermal conductive asphalt concrete. International Journal of Pavement Research and Technology, 2009, 2(4) 130-136.

[19] Chen, M., Wu, S., Zhang, Y. and Wang, H. Effects of conductive fillers on temperature distribution of asphalt pavements. Physica Scripta T, 2010, Vol. T139, art. no. 014046.

[20] Wang, H., Wu, S., Chen, M. and Zhang, Y. Numerical simulation on the thermal response of asphalt pavements. Physica Scripta T, 2010, Vol. T139, art. no. 014041.

[21] Wu, S., Chen, M. and Zhang, Y. Laboratory investigation into thermal response of asphalt pavements as solar collector by application of small-scale slabs. Applied Thermal Engineering, 2011, 31(10) 1582-1587.

[22] Chen, M., Wu, S., Wang, H. and Zhang, Y. Study of ice and snow melting process on conductive asphalt solar collector. Solar Energy Materials and Solar Cells, 2011, 95(12) 3241-3250.

[23] D'Antoni, M. and Saro, O. Massive Solar-Thermal Collectors: A critical literature review. Renewable and Sustainable Energy Reviews, 2012, 16 (2012) 3666-3679.

[24] Bobes-Jesus, V., Pascual-Muñoz, P., Castro-Fresno, D. and Rodriguez-Hernandez, J. Asphalt solar collectors: A literature review. Applied Energy, 2013, 102 pp. 962-970

[25] Moreno, F., Sol, M., Martín, J., Pérez, M. and Rubio, M.C. The effect of crumb rubber modifier on the resistance of asphalt mixes to plastic deformation. Materials and Design, 2013, 47 pp. 274-280.

[26] ISO 12543-4:2011. Glass in building. Laminated glass and laminated safety glass. Part 4: Test methods for durability.

[27] Bennet, F., Hart-Smith, G., Gruendling, T., Davis, T., Barker, P., and Barner-Kowollik, C. Degradation of Poly(methyl methacrylate) Model Compounds Under Extreme Environmental Conditions. Macromolecular Chemistry and Physics, 2010, 211(10) 1083-1097.

[28] Bernard, F., Quilgars, A., Cazaunau, M., Grosselin, B., Daele, V., Mellouki, A., Winterhalter, R. and Moortgat, G. Ozonolysis of a series of biogenic organic volatile compounds and secondary organic aerosol formation. Geophysical Research Abstracts, Volume 12. European Geosciences Union (EGU), General Assembly 2010. May 2-7, Vienna-Austria. 